\title{
Interactions of Ceftiofur Sodium with H2-Receptor Antagonist
}

\author{
N. TANDON*, RAAKHI GUPTA ${ }^{1}$ AND NEELIMA GUPTA ${ }^{2}$ \\ Lovely Professional University, School of Chemical Engineering and Physical Sciences, Phagwara-144411, ${ }^{1}$ Department of \\ Chemistry, IIS University, Jaipur, ${ }^{2}$ Department of Chemistry, University of Rajasthan, Jaipur, India
}

\section{Tandon et al.: Interactions of Ceftiofur Sodium with Famotidine}

\begin{abstract}
The purpose of this study was to examine the possible drug-drug interactions between ceftiofur sodium and famotidine on co-administration. These studies were carried out at normal as well as elevated temperature at $\mathrm{pH}$ corresponding to blood $\mathrm{pH}$ of 7.4 . Spectrophotometric method was used to study the dissolution of each drug individually and in the presence of the other drug. Change in the rate of dissolution of ceftiofur sodium in the presence of cimetidine as compared to the rate of dissolution in the absence of cimetidine supported the possible interactions between the two drugs.
\end{abstract}

Key words: $\mathrm{H}_{2}$-receptor antagonist, famotidine, absorbance, Beer-Lambert Law

Ceftiofur (fig. 1A) is a $3^{\text {rd }}$ generation cephalosporin antibiotic used as a veterinary medicine was marketed as a sterile powder containing sodium salt under the brand name Naxcel $^{\circledR}$ by Upjohn in 1988, which was delivered by intramuscular injection for the treatment of respiratory disease in beef cattle ${ }^{[1]}$. Ceftiofur contains oxyiminoaminothiazolyl group as the $7-\beta$-aminoacyl substituents of the 7 -aminocephalosporin nucleus. This substitution is also found in ceftriaxone, cefpodoxime, ceftazidime, cefotaxime, ceftizoxime and the monobactam, aztreonam. Ceftiofur contains the furoic acid thioester as one of the moieties, which is unique for $3^{\text {rd }}$ generation cephalosporins. Ceftiofur showed high in vitro activity against $M$. haemolytica, $P$. multocida, $A$. somnus, which are associated with respiratory diseases. It also shows in vitro activity against $E$. coli, Salmonella and early mortality associated with $E$. coli. In addition, it is used for treating foot rot and metritis in cattle. It has poor or no activity against species of Enterococcus and Pseudomonas species and thus is considered inactive against these organisms. Ceftiofur is not approved for treatment of enteric disease and has poor oral absorption properties. Therefore it has no oral formulation ${ }^{[2]}$.

Famotidine (fig. 1B) is a third generation $\mathrm{H}_{2}$-receptor antagonists that contains a thiazole ring. It is marketed under the trade name Pepcid and is approximately nine times more potent than cimetidine in suppressing

*Address for correspondence

E-mail: tandonnitin12004@gmail.com

January-February 2020 gastric acid secretion. It is a competitive inhibitor of histamine $\mathrm{H}_{2}$-receptor and inhibits basal and nocturnal gastric secretion as well as secretion stimulated by food and pentagastrin. It is also used for short term treatment of duodenal ulcer and treatment of pathologic hypersecretory conditions like Zollinger-Ellison syndrome. It has been reported that famotidine has no significant interactions with other drugs ${ }^{[3]}$.

Cephalosporins are well known to cause gastrointestinal complications due to which the use of acid suppressant drugs along with the cephalosporins are normally prescribed $^{[4]}$. $\mathrm{H}_{2}$-receptor antagonists are normally used to suppress the acid secretion associated with parietal cell and therefore are prescribed for various ulcer ${ }^{[5,6]}$ and gastro esophageal diseases ${ }^{[7]}$. There is a possibility that the simultaneous administration of cephalosporin and $\mathrm{H}_{2}$-receptor antagonist like famotidine can effect each other's bioavailability due to interactions. Number of reports are available in literature of interaction of cephalosporins with $\mathrm{H}_{2}$-receptor antagonist ${ }^{[8-19]}$. In continuation our focus to explore the possibility of interaction of ceftiofur sodium in the presence of

This is an open access article distributed under the terms of the Creative Commons Attribution-NonCommercial-ShareAlike 3.0 License, which allows others to remix, tweak, and build upon the work non-commercially, as long as the author is credited and the new creations are licensed under the identical terms

Accepted 04 December 2019 Revised 21 September 2019

Received 25 February 2019 Indian J Pharm Sci 2020;82(1):114-122 
A.

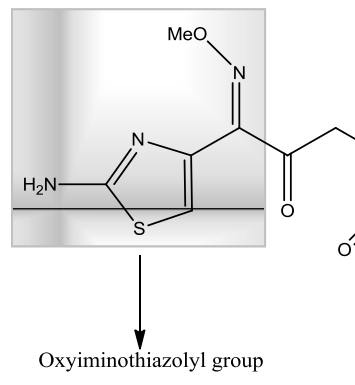

Fig. 1: Structures of (A) ceftiofur, (B) famotidine cimetidine $^{[20]}$, the present study reports the interaction of ceftiofur sodium and famotidine at a $\mathrm{pH} 7.4$ similar to that of the blood. Further, the studies were carried out at normal and elevated temperature.

\section{MATERIAL AND METHODS}

All chemicals used were of analytical grade. Reference standards of ceftiofur sodium and famotidine were received gratis from Macleods Pharmaceuticals, Mumbai. Powder formulation of ceftiofur sodium (Naxcel, $250 \mathrm{~g}$, Pfizer Inc.) and famotidine tablets (Pepcid, $40 \mathrm{mg}$, Merck) were obtained from local market. The water was double-distilled for making the required sample solutions and the absorbance of samples were measured by using UV spectrophotometer (Shimadzu UV-1800 ENG 240V1).

\section{Preparation of phosphate buffer of (pH 7.4):}

Disodium hydrogen phosphate $\left(\mathrm{Na}_{2} \mathrm{HPO}_{4} .12 \mathrm{H}_{2} \mathrm{O}\right.$; $17.90 \mathrm{~g})$ was dissolved in double-distilled water $(500 \mathrm{ml})$ in a volumetric flask. In another volumetric flask, solution of potassium dihydrogen phosphate $\left(\mathrm{KH}_{2} \mathrm{PO}_{4} ; 6.80 \mathrm{~g}\right)$ was prepared using double-distilled water $(100 \mathrm{ml})$. To prepare $1000 \mathrm{ml}$ of buffer of $\mathrm{pH}$ $7.4,31.4 \mathrm{ml}$ of disodium hydrogen phosphate solution and $5.7 \mathrm{ml}$ of potassium dihydrogen phosphate solution were mixed in a volumetric flask and the total volume was made $1000 \mathrm{ml}$ by adding double-distilled water. A few drops of disodium hydrogen phosphate solution were used to set the final $\mathrm{pH}$ to desired level.

\section{Preparation of stock and working solutions:}

Famotidine $(0.033 \mathrm{~g}, 0.1 \mathrm{mmol})$ and ceftiofur sodium (0.055 g, $0.1 \mathrm{mmol})$ were individually dissolved in double-distilled water and the volumes were made to $100 \mathrm{ml}$ in a volumetric flask to get the final concentration of $1 \mathrm{mM}$ for each stock solution. These stock solutions
B.

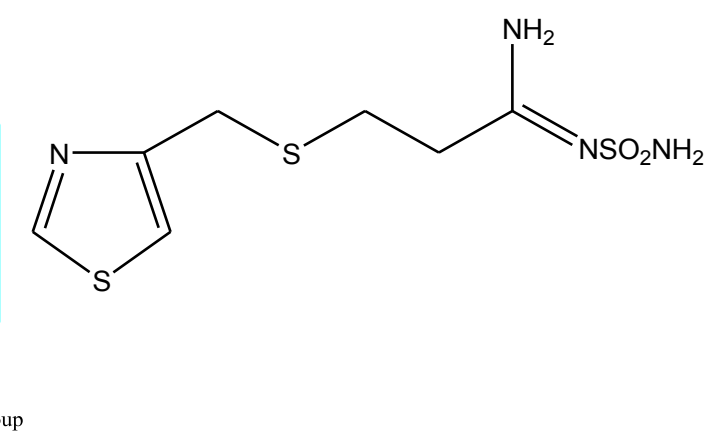

were further used to prepare the working solutions of different known concentrations from $0.01 \mathrm{mM}$ to $0.2 \mathrm{mM}$ for each drug. To achieve a concentration of $0.01 \mathrm{mM}, 1 \mathrm{ml}$ of the stock solution of each drug was added separately to $99 \mathrm{ml}$ of double-distilled water in $100 \mathrm{ml}$ volumetric flasks. In the same way, solutions of concentrations from $0.02-0.2 \mathrm{mM}$ for each drug were made by taking 2 to $20 \mathrm{ml}$ of stock solutions of each drug separately and adding $99 \mathrm{ml}$ double-distilled water in $100 \mathrm{ml}$ volumetric flasks.

\section{Measurement of $\lambda_{\max }$ for ceftiofur sodium and famotidine:}

The $\lambda_{\max }$ of famotidine and ceftiofur sodium reference standard were measured at $0.001 \mathrm{mM}$. This concentration was achieved by diluting $1 \mathrm{ml}$ of stock solution of each drug separately to $1000 \mathrm{ml}$ with double-distilled water in a 11 volumetric flask.

\section{Working concentration range for ceftiofur sodium and famotidine:}

To find out the concentration range for the proposed study, following of Beer-Lambert law was determined and validated. Working standards of famotidine and ceftiofur sodium in concentrations ranging from 0.01 to $0.2 \mathrm{mM}$ were prepared in 7.4 phosphate buffer solution. The absorption maxima for each of these solutions were scanned in the UV region against the blank. The ceftiofur sodium samples were scanned in the region of absorption maxima and at the maxima of famotidine against reagent blank. In the same way, famotidine samples were scanned at its own absorption maxima and at the absorption maxima of the ceftiofur. The graphs for concentration against absorption maxima were plotted, which resulted in straight lines to confirm linearity of Beer-Lambert law. These values were further used to calculate $\varepsilon$ values from the following Eqn., $\varepsilon=A /(b . C)$, where, A represented the absorbance at a certain wave 
length, $\varepsilon$ the molar absorptivity, $b$ the path length of cell and $\mathrm{C}$ the concentration of the solution.

\section{Dissolution studies of ceftiofur sodium and famotidine:}

Dissolution studies were carried out for both the drugs separately at $37^{\circ}$ and $60^{\circ}$. For this, famotidine $(40 \mathrm{mg}$ ) and ceftiofur sodium $(250 \mathrm{mg}$ in $5 \mathrm{ml}$ of doubledistilled water) were added in 11 buffer solution and each solution was maintained at specified temperature. Samples were withdrawn from both the solution after each $15 \mathrm{~min}$ for $4 \mathrm{~h}$ to calculate the drug content as per the following equation. In each case, the volume of the solution was maintained 11 with the use of buffer solution throughout the experiment. \% drug dissolved $=$ $(\mathrm{C} / \mathrm{x}) \times 100$, where, $\mathrm{C}$ is the concentration of the solution obtained from Beer-Lambert law, $\mathrm{x}=$ amount of the drug dissolved.

\section{Interaction studies between ceftiofur sodium and famotidine:}

Drug-drug interactions were studied at $37^{\circ}$ and $60^{\circ}$. For this, ceftiofur sodium $(250 \mathrm{mg}$ in $5 \mathrm{ml}$ of double-distilled water) was added to 11 of buffer solution at zero time and cimetidine (300 mg) was added to the solution after 15 min. Samples were taken after regular intervals of 15 min and were assayed for the concentration of the both the drugs according to the following Eqns., $\mathrm{C}_{\mathrm{a}}=$

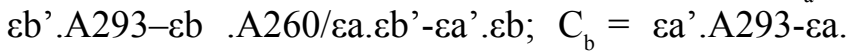

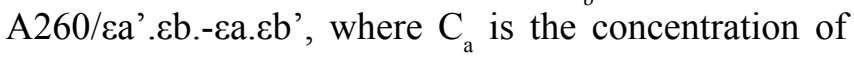
ceftiofur sodium, $\mathrm{C}_{\mathrm{b}}$ is the concentration of famotidine, $\varepsilon a$ and $\varepsilon b$ are the molar absorptivities of ceftiofur sodium and famotidine at $293 \mathrm{~nm}, \varepsilon \mathrm{a}$ ' and $\varepsilon$ ' are the molar absorptivities of ceftiofur sodium and famotidine at $260 \mathrm{~nm}$. Ceftiofur sodium samples were scanned in the region of its absorption maxima and at the absorption maxima of famotidine against region blank. In the same way, famotidine samples were scanned at its own absorption maxima and at the absorption maxima of the ceftiofur sodium.

\section{RESULTS AND DISCUSSION}

Ceftiofur sodium and famotidine $(0.0001 \mathrm{mmol})$ was scanned in the region of $150-400 \mathrm{~nm}$ individually to get $\lambda_{\max }$ of ceftiofur sodium at $293 \mathrm{~nm}$ and famotidine at $260 \mathrm{~nm}$ and $281 \mathrm{~nm}$. For the purpose of establishment of Beer-Lambert law, the working standard solution of ceftiofur sodium and famotidine were subjected to spectrophotometric analysis. The data is presented for both ceftiofur sodium and famotidine in Table 1 . The $\varepsilon$ values for each drug were calculated as in Tables 2 and
3. These values were further used for dissolution and drug interaction studies.

The dissolution studies for ceftiofur sodium and famotidine are summarized in Tables 4-6. It was clear from the dissolution study of famotidine at both the wavelengths that concentration of the drug at $281 \mathrm{~nm}$ reached $100 \%$ after 120 min only and therefore the results after this time were not valuable. On the other hand, the dissolution study could be done for longer duration at $260 \mathrm{~nm}$ where the drug showed maximum availability of $99 \%$ after $240 \mathrm{~min}$. Therefore $260 \mathrm{~nm}$ was the chosen wavelength for the study of interaction of this drug with ceftiofur sodium. Interaction studies of ceftiofur sodium and famotidine are presented in Tables 7 and 8 .

The graphical presentations of Beer-Lambert law for ceftiofur sodium and at their respective $\lambda_{\text {max }}$ values are shown in fig. 2. It is evident from the data that ceftiofur sodium obeyed Beer-Lambert law in the concentration range from 0.01-0.2 mmol whereas famotidine obeyed Beer-Lambert law at $260 \mathrm{~nm}$ only in the 0.01-0.1 mmol concentration range.

The rate of dissolution of ceftiofur sodium at $293 \mathrm{~nm}$ at normal $\left(37^{\circ}\right)$ indicated that the dissolution of the drug reaches to $91 \%$ after $15 \mathrm{~min}$ and attains a maximum value of $93 \%$ after $45 \mathrm{~min}$. After $45 \mathrm{~min}$, there was a steady decrease in the content of this drug with time reaching to a minimum value of $82 \%$ after $4 \mathrm{~h}$, which can be attributed to the degradation of ceftiofur sodium at $\mathrm{pH}$ 7.4. Similar trend has been reported in literature for cefixime ${ }^{[17]}$. This is in contrast to results reported for cephradine where its dissolution was found to increase with time in the presence of famotidine ${ }^{[14]}$.

At $60^{\circ}$, dissolution of ceftiofur sodium reaches to maximum value of $94 \%$ after $15 \mathrm{~min}$ and started to decrease thereafter reaching to a minimum value of $79 \%$ after $4 \mathrm{~h}$. It can be concluded that the dissolution of ceftiofur is more at high temperature after $15 \mathrm{~min}$ but reached to almost same value of $92 \%$ after $45 \mathrm{~min}$ at both the temperatures. In addition, the degradation of ceftiofur sodium is accelerated at higher temperature. This is in contrast to the results found in the case of cefixime ${ }^{[17]}$, where rise in temperature did not affect the stability of the drug.

The dissolution of famotidine at $260 \mathrm{~nm}$ showed that temperature has no effect on the solution stability of famotidine. Famotidine showed almost same dissolution at both the temperatures. Almost $82 \%$ of famotidine dissolved after $15 \mathrm{~min}$ in both the cases 


\begin{tabular}{|c|c|c|c|c|c|}
\hline \multirow{2}{*}{ Stock (ml) } & \multirow{2}{*}{ Buffer (ml) } & \multirow{2}{*}{ Conc. (mmol) } & \multicolumn{3}{|c|}{ Absorbance at $\lambda \max$} \\
\hline & & & $293 \mathrm{~nm}$ & $260 \mathrm{~nm}$ & $281 \mathrm{~nm}$ \\
\hline \multicolumn{6}{|c|}{ Ceftiofur sodium } \\
\hline 1 & 99 & 0.01 & 0.230 & 0.143 & 0.200 \\
\hline 2 & 98 & 0.02 & 0.481 & 0.323 & 0.444 \\
\hline 3 & 97 & 0.03 & 0.803 & 0.590 & 0.710 \\
\hline 4 & 96 & 0.04 & 1.012 & 0.700 & 0.880 \\
\hline 5 & 95 & 0.05 & 1.441 & 0.800 & 1.090 \\
\hline 6 & 94 & 0.06 & 1.460 & 0.832 & 1.122 \\
\hline 7 & 93 & 0.07 & 1.660 & 1.020 & 1.400 \\
\hline 8 & 92 & 0.08 & 1.844 & 1.161 & 1.55 \\
\hline 9 & 91 & 0.09 & 1.681 & 1.200 & 1.410 \\
\hline 10 & 90 & 0.10 & 1.955 & 1.411 & 1.305 \\
\hline 11 & 89 & 0.11 & 2.391 & 1.511 & 1.580 \\
\hline 12 & 88 & 0.12 & 2.631 & 1.780 & 2.25 \\
\hline 13 & 87 & 0.13 & 2.840 & 1.144 & 2.400 \\
\hline 14 & 86 & 0.14 & 3.267 & 2.451 & 2.773 \\
\hline 15 & 85 & 0.15 & 3.462 & 2.140 & 2.950 \\
\hline 16 & 84 & 0.16 & 3.701 & 2.311 & 3.151 \\
\hline 17 & 83 & 0.17 & 3.622 & 2.654 & 3.080 \\
\hline 18 & 82 & 0.18 & 3.819 & 2.980 & 3.545 \\
\hline 19 & 81 & 0.19 & 4.051 & 2.443 & 3.783 \\
\hline 20 & 80 & 0.20 & 4.150 & 3.060 & 3.802 \\
\hline \multicolumn{6}{|l|}{ Famotidine } \\
\hline 1 & 99 & 0.01 & 0.151 & 0.247 & 0.251 \\
\hline 2 & 98 & 0.02 & 0.261 & 0.465 & 0.261 \\
\hline 3 & 97 & 0.03 & 0.373 & 0.696 & 0.406 \\
\hline 4 & 96 & 0.04 & 0.466 & 0.864 & 0.508 \\
\hline 5 & 95 & 0.05 & 0.619 & 1.122 & 0.674 \\
\hline 6 & 94 & 0.06 & 0.698 & 1.261 & 0.761 \\
\hline 7 & 93 & 0.07 & 0.806 & 1.418 & 0.881 \\
\hline 8 & 92 & 0.08 & 0.919 & 1.602 & 0.998 \\
\hline 9 & 91 & 0.09 & 1.043 & 1.74 & 1.139 \\
\hline 10 & 90 & 0.10 & 1.148 & 1.909 & 1.252 \\
\hline 11 & 89 & 0.11 & 1.277 & 1.949 & 1.394 \\
\hline 12 & 88 & 0.12 & 1.375 & 2.134 & 1.505 \\
\hline 13 & 87 & 0.13 & 1.443 & 2.050 & 1.576 \\
\hline 14 & 86 & 0.14 & 1.578 & 2.110 & 1.723 \\
\hline 15 & 85 & 0.15 & 1.673 & 2.155 & 1.821 \\
\hline 16 & 84 & 0.16 & 1.754 & 2.153 & 1.921 \\
\hline 17 & 83 & 0.17 & 1.866 & 2.260 & 2.009 \\
\hline 18 & 82 & 0.18 & 2.017 & 2.368 & 2.119 \\
\hline 19 & 81 & 0.19 & 0.151 & 0.247 & 0.251 \\
\hline 20 & 80 & 0.20 & 0.261 & 0.465 & 0.261 \\
\hline
\end{tabular}

which increases steadily with time till 105 min. Post $105 \mathrm{~min}$, famotidine showed slightly more solubility at $60^{\circ}$ as compared to at $37^{\circ}$ till $150 \mathrm{~min}(88 \%$ vs. $90 \%$ solubility at $37^{\circ}$ and $60^{\circ}$, respectively). After $150 \mathrm{~min}$ at both the temperatures famotidine solubility reached a maximum value of $96 \%$ up to $240 \mathrm{~min}$.

The solubility of famotidine at $281 \mathrm{~nm}$ and $37^{\circ}$ indicated that famotidine dissolved up to $82 \%$ after $15 \mathrm{~min}$, which increased with time to reach $100 \%$ after $180 \mathrm{~min}$. On the other hand at $60^{\circ}$, more than $90 \%$ of the famotidine dissolved after $15 \mathrm{~min}$ and almost $100 \%$ of famotidine is available in solution after $120 \mathrm{~min}$. Comparison of the solubilities at both temperatures showed that high temperature assisted in quick dissolution of famotidine ( $92 \%$ at $60^{\circ}$ as compared to $82 \%$ at $37^{\circ}$ after $15 \mathrm{~min}$ ). Also, there is sharper increase dissolution of the drug with time at higher temperature as it reaches $100 \%$ after $120 \mathrm{~min}$ at $60^{\circ}$ as compared to $180 \mathrm{~min}$ at $37^{\circ}$. The 
TABLE 2: $\varepsilon$ VALUE OF FAMOTIDINE

\begin{tabular}{|c|c|c|c|c|c|c|}
\hline \multirow{2}{*}{ Concentration (M) } & \multicolumn{3}{|c|}{ Absorbance at $\lambda \max$} & \multicolumn{3}{|c|}{$\varepsilon=$ absorbance/(conc $x$ path length) } \\
\hline & $293 \mathrm{~nm}^{\mathrm{a}}$ & $260 \mathrm{~nm}^{\mathrm{b}}$ & $281 \mathrm{~nm}^{\mathrm{b}}$ & $\varepsilon 293$ & $\varepsilon 260$ & $\varepsilon 281$ \\
\hline 0.00001 & 0.151 & 0.247 & 0.251 & 15100.00 & 24700.00 & 25100.00 \\
\hline 0.00002 & 0.261 & 0.465 & 0.261 & 13050.00 & 23250.00 & 13050.00 \\
\hline 0.00003 & 0.373 & 0.696 & 0.406 & 12433.33 & 23200.00 & 13533.33 \\
\hline 0.00004 & 0.466 & 0.864 & 0.508 & 11650.00 & 21600.00 & 12700.00 \\
\hline 0.00005 & 0.619 & 1.122 & 0.674 & 12380.00 & 22440.00 & 13480.00 \\
\hline 0.00006 & 0.698 & 1.261 & 0.761 & 11633.33 & 21016.67 & 12683.33 \\
\hline 0.00007 & 0.806 & 1.418 & 0.881 & 11514.29 & 20257.14 & 12585.71 \\
\hline 0.00008 & 0.919 & 1.602 & 0.998 & 11487.5 & 20025.00 & 12475.00 \\
\hline 0.00009 & 1.043 & 1.74 & 1.139 & 11588.89 & 19333.33 & 12655.56 \\
\hline 0.0001 & 1.148 & 1.909 & 1.252 & 11480.00 & 19090.00 & 12520.00 \\
\hline 0.00011 & 1.277 & 1.949 & 1.394 & 11609.09 & 17718.18 & 12672.73 \\
\hline 0.00012 & 1.375 & 2.134 & 1.505 & 11458.33 & 17783.33 & 12541.67 \\
\hline 0.00013 & 1.443 & 2.050 & 1.576 & 11100.00 & - & 12123.08 \\
\hline 0.00014 & 1.578 & 2.110 & 1.723 & 11271.43 & - & 12307.14 \\
\hline 0.00015 & 1.673 & 2.155 & 1.821 & 11153.33 & - & 12140.00 \\
\hline 0.00016 & 1.754 & 2.153 & 1.921 & 10962.50 & - & 12006.25 \\
\hline 0.00017 & 1.866 & 2.260 & 2.009 & 10976.47 & - & 11817.65 \\
\hline 0.00018 & 2.017 & 2.368 & 2.119 & 11205.56 & - & 11772.22 \\
\hline 0.00019 & 2.016 & 2.203 & 2.119 & 10610.53 & - & 11152.63 \\
\hline \multirow[t]{3}{*}{0.0002} & 2.118 & 2.231 & 2.296 & 10590.00 & - & 11480.00 \\
\hline & & & Summation & 230804.00 & 214912.00 & 250696.00 \\
\hline & & & Mean & 11540 & 21491 & 12534 \\
\hline
\end{tabular}

TABLE 3: $\varepsilon$ VALUE OF CEFTIOFUR SODIUM

\begin{tabular}{|c|c|c|c|c|c|c|}
\hline \multirow{2}{*}{ Conc. (M) } & \multicolumn{3}{|c|}{ Absorbance at $\lambda \max$} & \multicolumn{3}{|c|}{$\varepsilon=$ absorbance/(conc $X$ path length) } \\
\hline & $293 \mathrm{~nm}^{\mathrm{a}}$ & $260 \mathrm{~nm}^{\mathrm{b}}$ & $281 \mathrm{~nm}^{\mathrm{b}}$ & $293 \mathrm{~nm}$ & $260 \mathrm{~nm}$ & $281 \mathrm{~nm}$ \\
\hline 0.00001 & 0.230 & 0.143 & 0.200 & 23000 & 14300 & 20000 \\
\hline 0.00002 & 0.481 & 0.323 & 0.444 & 24050 & 16150 & 22200 \\
\hline 0.00003 & 0.803 & 0.590 & 0.710 & 26766 & 19666 & 23666 \\
\hline 0.00004 & 1.012 & 0.700 & 0.880 & 25300 & 17500 & 22000 \\
\hline 0.00005 & 1.441 & 0.800 & 1.090 & 28820 & 16000 & 21800 \\
\hline 0.00006 & 1.460 & 0.832 & 1.122 & 24333 & 13866 & 18700 \\
\hline 0.00007 & 1.660 & 1.020 & 1.400 & 23714 & 14571 & 20000 \\
\hline 0.00008 & 1.844 & 1.161 & 1.55 & 23050 & 14512 & 19375 \\
\hline 0.00009 & 1.681 & 1.200 & 1.410 & 18677 & 13333 & 15666 \\
\hline 0.0001 & 1.955 & 1.411 & 1.305 & 19550 & 14110 & 13050 \\
\hline 0.00011 & 2.391 & 1.511 & 1.580 & 21736 & 13736 & 14363 \\
\hline 0.00012 & 2.631 & 1.780 & 2.25 & 21925 & 14833 & 18750 \\
\hline 0.00013 & 2.840 & 1.144 & 2.400 & 21846 & 8800 & 18461 \\
\hline 0.00014 & 3.267 & 2.451 & 2.773 & 23335 & 17507 & 19807 \\
\hline 0.00015 & 3.462 & 2.140 & 2.950 & 23080 & 14266 & 19666 \\
\hline 0.00016 & 3.701 & 2.311 & 3.151 & 23131 & 14443 & 19693 \\
\hline 0.00017 & 3.622 & 2.654 & 3.080 & 21305 & 15611 & 18117 \\
\hline 0.00018 & 3.819 & 2.980 & 3.545 & 21216 & 16555 & 19694 \\
\hline 0.00019 & 4.051 & 2.443 & 3.783 & 21321 & 12857 & 19910 \\
\hline \multirow[t]{3}{*}{0.0002} & 4.150 & 3.060 & 3.802 & 20750 & 15300 & 19010 \\
\hline & & & Summation & 456910 & 297923 & 383933 \\
\hline & & & Mean & 22845 & 14896 & 19196 \\
\hline
\end{tabular}

results found are in consistent with the results reported of famotidine with increase in time and temperature by Arayne et al..$^{[17]}$ where the increase in the availability was reported at $\mathrm{pH}=7.4$. 
TABLE 4: RATE OF DISSOLUTION OF CEFTIOFUR SODIUM AT $\lambda 293 \mathrm{~nm}$

\begin{tabular}{|c|c|c|c|}
\hline $\begin{array}{l}\text { Time } \\
(\min )\end{array}$ & Absorbance & $\begin{array}{c}\text { Concentration } \\
(M)\end{array}$ & $\begin{array}{l}\% \text { of drug } \\
\text { dissolved }\end{array}$ \\
\hline \multicolumn{4}{|l|}{ At $37^{\circ}$} \\
\hline 15 & 0.9511 & $4.1632 \times 10^{-5}$ & 90.9 \\
\hline 30 & 0.9671 & $4.2333 \times 10^{-5}$ & 92.43 \\
\hline 45 & 0.9678 & $4.2365 \times 10^{-5}$ & 92.5 \\
\hline 60 & 0.9649 & $4.2237 \times 10^{-5}$ & 92.22 \\
\hline 75 & 0.9590 & $4.1980 \times 10^{-5}$ & 91.66 \\
\hline 90 & 0.9540 & $4.1760 \times 10^{-5}$ & 91.18 \\
\hline 105 & 0.9380 & $4.1060 \times 10^{-5}$ & 89.65 \\
\hline 120 & 0.9321 & $4.0803 \times 10^{-5}$ & 89.09 \\
\hline 135 & 0.9053 & $3.9626 \times 10^{-5}$ & 86.52 \\
\hline 150 & 0.9038 & $3.9562 \times 10^{-5}$ & 86.38 \\
\hline 165 & 0.8966 & $3.9246 \times 10^{-5}$ & 85.69 \\
\hline 180 & 0.8813 & $3.8577 \times 10^{-5}$ & 84.23 \\
\hline 195 & 0.8763 & $3.8358 \times 10^{-5}$ & 83.75 \\
\hline 210 & 0.8668 & $3.7941 \times 10^{-5}$ & 82.84 \\
\hline 225 & 0.8588 & $3.7593 \times 10^{-5}$ & 82.08 \\
\hline 240 & 0.8551 & $3.7432 \times 10^{-5}$ & 81.73 \\
\hline \multicolumn{4}{|l|}{ At $60^{\circ}$} \\
\hline 15 & 0.9880 & $4.3249 \times 10^{-5}$ & 94.43 \\
\hline 30 & 0.9837 & $4.3061 \times 10^{-5}$ & 94.02 \\
\hline 45 & 0.9707 & $4.2489 \times 10^{-5}$ & 92.77 \\
\hline 60 & 0.9511 & $4.1632 \times 10^{-5}$ & 90.9 \\
\hline 75 & 0.9104 & $3.9851 \times 10^{-5}$ & 87.01 \\
\hline 90 & 0.8690 & $3.8037 \times 10^{-5}$ & 83.05 \\
\hline 105 & 0.8675 & $3.7973 \times 10^{-5}$ & 82.91 \\
\hline 120 & 0.8617 & $3.7721 \times 10^{-5}$ & 82.36 \\
\hline 135 & 0.8603 & $3.7657 \times 10^{-5}$ & 82.22 \\
\hline 150 & 0.8595 & $3.7625 \times 10^{-5}$ & 82.15 \\
\hline 165 & 0.8588 & $3.7593 \times 10^{-5}$ & 82.08 \\
\hline 180 & 0.8581 & $3.7561 \times 10^{-5}$ & 82.01 \\
\hline 195 & 0.8443 & $3.6956 \times 10^{-5}$ & 80.69 \\
\hline 210 & 0.8348 & $3.6544 \times 10^{-5}$ & 79.79 \\
\hline 225 & 0.8304 & $3.6351 \times 10^{-5}$ & 79.37 \\
\hline 240 & 0.8283 & $3.6255 \times 10^{-5}$ & 79.16 \\
\hline
\end{tabular}

The comparison of the dissolution of ceftiofur sodium in the presence and absence of famotidine at $37^{\circ}$ and $60^{\circ}$ is represented as \% of drug dissolved vs. time (Table 7). It is clear from the Table that as compared to the dissolution of ceftiofur sodium alone, the presence of famotidine assisted in the initial dissolution of ceftiofur till $15 \mathrm{~min}$ (96\% after $15 \mathrm{~min}$ in the presence of famotidine as compared to $91 \%$ alone). Post $15 \mathrm{~min}$, the dissolution of ceftiofur started to decrease with time and this decrease is sharper in the presence of famotidine reaching to minimum value of $61 \%$ as compared to availability of $82 \%$ in the absence of famotidine.

On comparison of solubility of ceftiofur sodium in the presence and absence of famotidine at $60^{\circ}$, it was observed that ceftiofur is almost $100 \%$ dissolved after $15 \mathrm{~min}$ in the presence of famotidine. After $15 \mathrm{~min}$, the amount of ceftiofur in solution decreased but not to the same extent when ceftiofur alone decreased till $45 \mathrm{~min}$. Post 45 min, a sharp decrease in the content of ceftiofur was observed in the presence of famotidine reaching to a minimum value of $47 \%$ as compared to the $79 \%$ in the absence.

On comparing the solubility of ceftiofur sodium in the presence of famotidine at $37^{\circ}$ and $60^{\circ}$. As it is clear that at high temperature, famotidine assisted the quick dissolution of ceftiofur and almost $100 \%$ is dissolved after $15 \mathrm{~min}$ at $60^{\circ}$ as compared to $96 \%$ at $37^{\circ}$. After $15 \mathrm{~min}$, the drug content decreased with time at both the temperatures. From 15 to $45 \mathrm{~min}$, the drug content was more at $60^{\circ}$ as compared to the same at $37^{\circ}$. Post

TABLE 5: RATE OF DISSOLUTION OF FAMOTIDINE AT $\lambda 260 \mathrm{~nm}$

\begin{tabular}{|c|c|c|c|}
\hline $\begin{array}{l}\text { Time } \\
\text { (min) }\end{array}$ & Absorbance & $\begin{array}{c}\text { Concentration } \\
\text { (M) }\end{array}$ & $\begin{array}{l}\text { \% of drug } \\
\text { dissolved }\end{array}$ \\
\hline \multicolumn{4}{|l|}{ At $37^{\circ}$} \\
\hline 15 & 0.2103 & $9.7854 \times 10^{-6}$ & 82.23 \\
\hline 30 & 0.2135 & $9.9341 \times 10^{-6}$ & 83.48 \\
\hline 45 & 0.2144 & $9.9782 \times 10^{-6}$ & 83.85 \\
\hline 60 & 0.2147 & $9.9924 \times 10^{-6}$ & 83.97 \\
\hline 75 & 0.2162 & $1.0059 \times 10^{-5}$ & 84.53 \\
\hline 90 & 0.2165 & $1.0075 \times 10^{-5}$ & 84.66 \\
\hline 105 & 0.2219 & $1.0324 \times 10^{-5}$ & 86.76 \\
\hline 120 & 0.2217 & $1.0315 \times 10^{-5}$ & 86.68 \\
\hline 135 & 0.2258 & $1.0508 \times 10^{-5}$ & 88.3 \\
\hline 150 & 0.2266 & $1.0546 \times 10^{-5}$ & 88.62 \\
\hline 165 & 0.2288 & $1.0647 \times 10^{-5}$ & 89.47 \\
\hline 180 & 0.2366 & $1.1009 \times 10^{-5}$ & 92.51 \\
\hline 195 & 0.2430 & $1.1307 \times 10^{-5}$ & 95.02 \\
\hline 210 & 0.2431 & $1.1312 \times 10^{-5}$ & 95.06 \\
\hline 225 & 0.2434 & $1.1326 \times 10^{-5}$ & 95.18 \\
\hline 240 & 0.2455 & $1.1423 \times 10^{-5}$ & 95.99 \\
\hline \multicolumn{4}{|l|}{ At $60^{\circ}$} \\
\hline 15 & 0.2126 & $9.8937 \times 10^{-6}$ & 83.14 \\
\hline 30 & 0.2131 & $9.9151 \times 10^{-6}$ & 83.32 \\
\hline 45 & 0.2151 & $1.0011 \times 10^{-5}$ & 84.12 \\
\hline 60 & 0.2163 & $1.0063 \times 10^{-5}$ & 84.56 \\
\hline 75 & 0.2174 & $1.0116 \times 10^{-5}$ & 85.01 \\
\hline 90 & 0.2176 & $1.0126 \times 10^{-5}$ & 85.09 \\
\hline 105 & 0.2194 & $1.0208 \times 10^{-5}$ & 85.78 \\
\hline 120 & 0.2270 & $1.0562 \times 10^{-5}$ & 88.76 \\
\hline 135 & 0.2276 & $1.0589 \times 10^{-5}$ & 88.98 \\
\hline 150 & 0.2308 & $1.0737 \times 10^{-5}$ & 90.23 \\
\hline 165 & 0.2310 & $1.0750 \times 10^{-5}$ & 90.34 \\
\hline 180 & 0.2381 & $1.1079 \times 10^{-5}$ & 93.10 \\
\hline 195 & 0.2393 & $1.1136 \times 10^{-5}$ & 93.58 \\
\hline 210 & 0.2416 & $1.1242 \times 10^{-5}$ & 94.47 \\
\hline 225 & 0.2444 & $1.1374 \times 10^{-5}$ & 95.58 \\
\hline 240 & 0.2465 & $1.1470 \times 10^{-5}$ & 96.39 \\
\hline
\end{tabular}


TABLE 6: RATE OF DISSOLUTION OF FAMOTIDINE AT $\lambda 281 \mathrm{~nm}$

\begin{tabular}{|c|c|c|c|}
\hline Time (min.) & Absorbance & $\begin{array}{c}\text { Concentration } \\
\text { (M) }\end{array}$ & $\begin{array}{l}\text { \% of drug } \\
\text { dissolved }\end{array}$ \\
\hline \multicolumn{4}{|l|}{ At $37^{\circ}$} \\
\hline 15 & 0.1225 & $9.7735 \times 10^{-6}$ & 82.13 \\
\hline 30 & 0.1261 & $1.0063 \times 10^{-5}$ & 84.56 \\
\hline 45 & 0.1337 & $1.0668 \times 10^{-5}$ & 89.65 \\
\hline 60 & 0.1344 & $1.0721 \times 10^{-5}$ & 90.09 \\
\hline 75 & 0.1379 & $1.1000 \times 10^{-5}$ & 92.44 \\
\hline 90 & 0.1395 & $1.1134 \times 10^{-5}$ & 93.56 \\
\hline 105 & 0.1427 & $1.1382 \times 10^{-5}$ & 95.65 \\
\hline 120 & 0.1438 & $1.1475 \times 10^{-5}$ & 96.43 \\
\hline 135 & 0.1475 & $1.1768 \times 10^{-5}$ & 98.89 \\
\hline 150 & 0.1482 & $1.1821 \times 10^{-5}$ & 99.34 \\
\hline 165 & 0.1490 & $1.1885 \times 10^{-5}$ & 99.87 \\
\hline 180 & 0.1492 & $1.1901 \times 10^{-5}$ & 100.01 \\
\hline 195 & 0.1490 & $1.1887 \times 10^{-5}$ & 99.89 \\
\hline 210 & 0.1491 & $1.1899 \times 10^{-5}$ & 99.99 \\
\hline 225 & 0.1493 & $1.1908 \times 10^{-5}$ & 100.07 \\
\hline 240 & 0.1491 & $1.1899 \times 10^{-5}$ & 99.99 \\
\hline \multicolumn{4}{|l|}{ At $60^{\circ}$} \\
\hline 15 & 0.1374 & $1.0962 \times 10^{-5}$ & 92.12 \\
\hline 30 & 0.1398 & $1.1157 \times 10^{-5}$ & 93.76 \\
\hline 45 & 0.1415 & $1.1290 \times 10^{-5}$ & 94.87 \\
\hline 60 & 0.1452 & $1.1583 \times 10^{-5}$ & 97.34 \\
\hline 75 & 0.1463 & $1.1675 \times 10^{-5}$ & 98.11 \\
\hline 90 & 0.1470 & $1.1726 \times 10^{-5}$ & 98.54 \\
\hline 105 & 0.1477 & $1.1785 \times 10^{-5}$ & 99.03 \\
\hline 120 & 0.1487 & $1.1861 \times 10^{-5}$ & 99.67 \\
\hline 135 & 0.1494 & $1.1918 \times 10^{-5}$ & 100.15 \\
\hline 150 & 0.1496 & $1.1935 \times 10^{-5}$ & 100.29 \\
\hline 165 & 0.1491 & $1.1899 \times 10^{-5}$ & 99.99 \\
\hline 180 & 0.1497 & $1.1942 \times 10^{-5}$ & 100.35 \\
\hline 195 & 0.1497 & $1.1946 \times 10^{-5}$ & 100.39 \\
\hline 210 & 0.1507 & $1.2020 \times 10^{-5}$ & 101.01 \\
\hline 225 & 0.1500 & $1.1967 \times 10^{-5}$ & 100.56 \\
\hline 240 & 0.1503 & $1.1993 \times 10^{-5}$ & 100.78 \\
\hline
\end{tabular}

$60 \mathrm{~min}$, sharp decrease in the drug content with time was observed at $60^{\circ}$ as compared to the same at $37^{\circ}$ reaching to a minimum value of $46 \%$ as compared to $61 \%$ at $60^{\circ}$ and $37^{\circ}$, respectively. In vivo studies of cefpodoxime in the presence of famotidine also showed the decrease in the availability of the antibiotic in the presence of the famotidine ${ }^{[19]}$.

These results showed that famotidine interacted with ceftiofur sodium as shown by the change in the solubility of ceftiofur sodium in the combined presence. Further, it

TABLE 7: CEFTIOFUR SODIUM AND FAMOTIDINE INTERACTIONS AT $260 \mathrm{~nm}$ AT $37^{\circ}$

\begin{tabular}{|c|c|c|c|c|}
\hline $\begin{array}{l}\text { Time } \\
\text { (min) }\end{array}$ & A293 & A260 & $\begin{array}{c}\% \text { of } \\
\text { ceftio- } \\
\text { furso } \\
\text { dium }\end{array}$ & $\begin{array}{l}\% \text { of } \\
\text { famo- } \\
\text { tidine }\end{array}$ \\
\hline 0 & 1.0598 & $0.74844 .4318 \times 10^{-5} 4.1048 \times 10^{-6}$ & 96.68 & 34.64 \\
\hline 15 & 1.1236 & $0.88004 .3855 \times 10^{-5} 1.055 \times 10^{-5}$ & 95.67 & 89.03 \\
\hline 30 & 1.0812 & $0.86884 .1403 \times 10^{-5} 1.1729 \times 10^{-5}$ & 90.32 & 98.98 \\
\hline 45 & 1.0858 & $0.88044 .1293 \times 10^{-5} 1.2343 \times 10^{-5}$ & 90.08 & 104.16 \\
\hline 60 & 1.0703 & $0.87244 .0536 \times 10^{-5} 1.2497 \times 10^{-5}$ & 88.43 & 105.46 \\
\hline 75 & 1.0474 & $0.85673 .9565 \times 10^{-5} 1.244 \times 10^{-5}$ & 86.31 & 104.98 \\
\hline 90 & 1.0199 & $0.83913 .8350 \times 10^{-5} 1.2465 \times 10^{-5}$ & 83.66 & 105.19 \\
\hline 105 & 0.9900 & $0.82013 .7020 \times 10^{-5} 1.2498 \times 10^{-5}$ & 80.76 & 105.47 \\
\hline 120 & 0.9415 & $0.78923 .4875 \times 10^{-5} 1.2548 \times 10^{-5}$ & 76.08 & 105.89 \\
\hline 135 & 0.8799 & $0.74973 .2152 \times 10^{-5} 1.2599 \times 10^{-5}$ & 70.14 & 106.32 \\
\hline 150 & 0.8402 & $0.72273 .0452 \times 10^{-5} 1.2522 \times 10^{-5}$ & 66.43 & 105.67 \\
\hline 165 & 0.8376 & $0.72243 .0291 \times 10^{-5} 1.2618 \times 10^{-5}$ & 66.08 & 106.48 \\
\hline 180 & 0.8432 & $0.72543 .0557 \times 10^{-5} 1.2574 \times 10^{-5}$ & 66.66 & 106.11 \\
\hline 195 & 0.8067 & $0.70022 .9008 \times 10^{-5} 1.2477 \times 10^{-5}$ & 63.28 & 105.29 \\
\hline 210 & 0.7856 & $0.68932 .7985 \times 10^{-5} 1.2678 \times 10^{-5}$ & 61.05 & 106.99 \\
\hline 225 & 0.7908 & $0.69112 .8270 \times 10^{-5} 1.2561 \times 10^{-5}$ & 61.67 & 106.00 \\
\hline 240 & 0.7846 & $0.68982 .7903 \times 10^{-5} 1.2755 \times 10^{-5}$ & 60.87 & 107.64 \\
\hline
\end{tabular}

TABLE 8: CEFTIOFUR SODIUM AND FAMOTIDINE INTERACTIONS AT $260 \mathrm{~nm}$ AT $60^{\circ}$

\begin{tabular}{lllllll}
\hline Time (min) & A293 & A260 & Ca $^{\mathrm{a}}$ & $\mathrm{Cb}^{\mathrm{b}}$ & \% of ceftiofursodium & \% of famotidine \\
\hline 0 & 1.3186 & 0.9520 & $5.4389 \times 10^{-5}$ & $6.5969 \times 10^{-6}$ & 118.65 & 55.67 \\
15 & 1.1814 & 0.9232 & $4.6188 \times 10^{-5}$ & $1.0942 \times 10^{-5}$ & 100.76 & 92.34 \\
30 & 1.1330 & 0.9019 & $4.3695 \times 10^{-5}$ & $1.1679 \times 10^{-5}$ & 95.32 & 98.56 \\
45 & 1.1322 & 0.9061 & $4.3488 \times 10^{-5}$ & $1.2019 \times 10^{-5}$ & 94.87 & 101.43 \\
60 & 1.0659 & 0.8632 & $4.0573 \times 10^{-5}$ & $1.2046 \times 10^{-5}$ & 88.51 & 101.65 \\
75 & 1.0147 & 0.8365 & $3.8093 \times 10^{-5}$ & $1.2520 \times 10^{-5}$ & 83.1 & 105.65 \\
90 & 0.9879 & 0.8249 & $3.6704 \times 10^{-5}$ & $1.2943 \times 10^{-5}$ & 80.07 & 109.22 \\
105 & 0.9494 & 0.7994 & $3.5036 \times 10^{-5}$ & $1.2914 \times 10^{-5}$ & 76.43 & 108.98 \\
120 & 0.8920 & 0.7633 & $3.2478 \times 10^{-5}$ & $1.3007 \times 10^{-5}$ & 70.85 & 109.76 \\
135 & 0.8973 & 0.7672 & $3.2693 \times 10^{-5}$ & $1.3036 \times 10^{-5}$ & 71.32 & 110.01 \\
150 & 0.8912 & 0.7642 & $3.2386 \times 10^{-5}$ & $1.3112 \times 10^{-5}$ & 70.65 & 110.65 \\
165 & 0.8510 & 0.7373 & $3.0653 \times 10^{-5}$ & $1.3062 \times 10^{-5}$ & 66.87 & 110.23 \\
180 & 0.7802 & 0.6910 & $2.7564 \times 10^{-5}$ & $1.3046 \times 10^{-5}$ & 60.13 & 110.09 \\
195 & 0.7475 & 0.6711 & $2.6078 \times 10^{-5}$ & $1.3151 \times 10^{-5}$ & 56.89 & 110.98 \\
210 & 0.6984 & 0.6395 & $2.3915 \times 10^{-5}$ & $1.3181 \times 10^{-5}$ & 52.17 & 111.23 \\
225 & 0.6849 & 0.6303 & $2.3337 \times 10^{-5}$ & $1.3154 \times 10^{-5}$ & 50.91 & 111 \\
240 & 0.6460 & 0.6116 & $2.1389 \times 10^{-5}$ & $1.3635 \times 10^{-5}$ & 46.66 & 115.06 \\
\hline
\end{tabular}

$\mathrm{C}_{\mathrm{a}} \mathrm{a}=$ concentration of ceftiofur sodium, $\mathrm{C}_{\mathrm{b}}{ }^{\mathrm{b}}=$ concentration of famotidine 

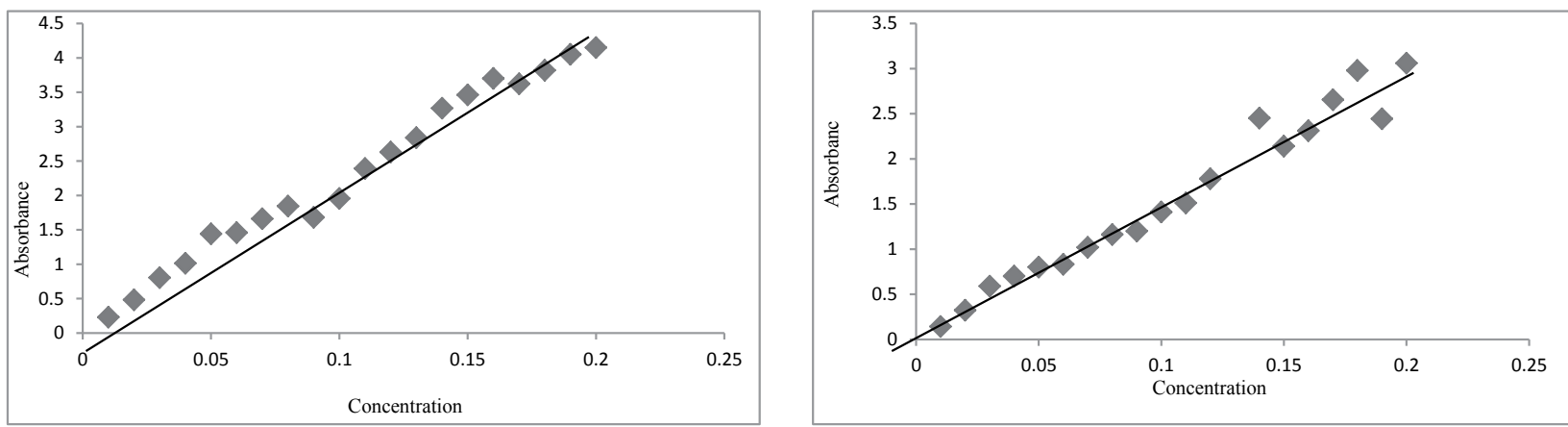

B
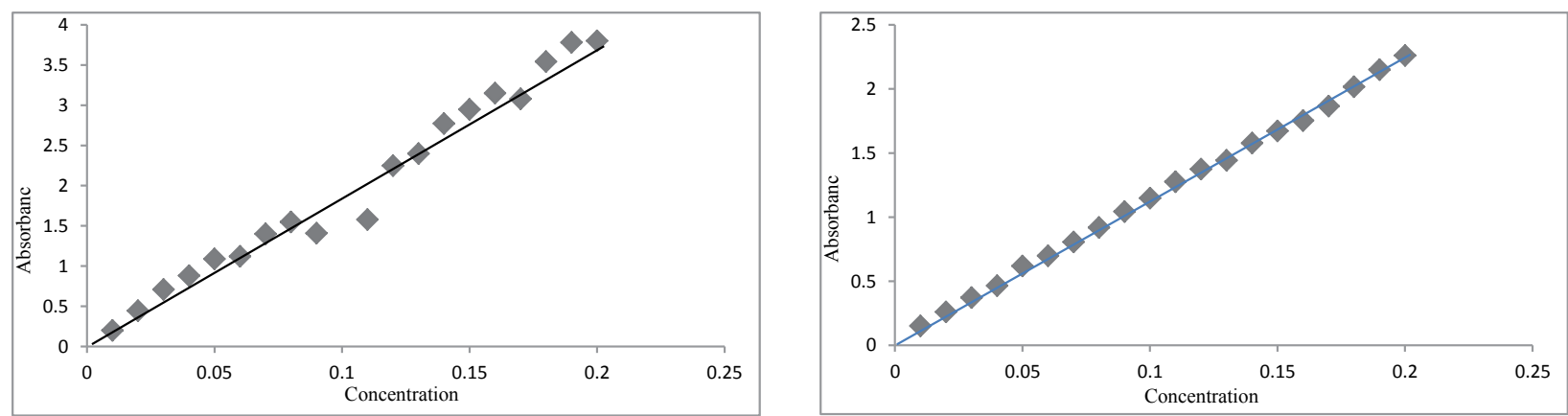

C

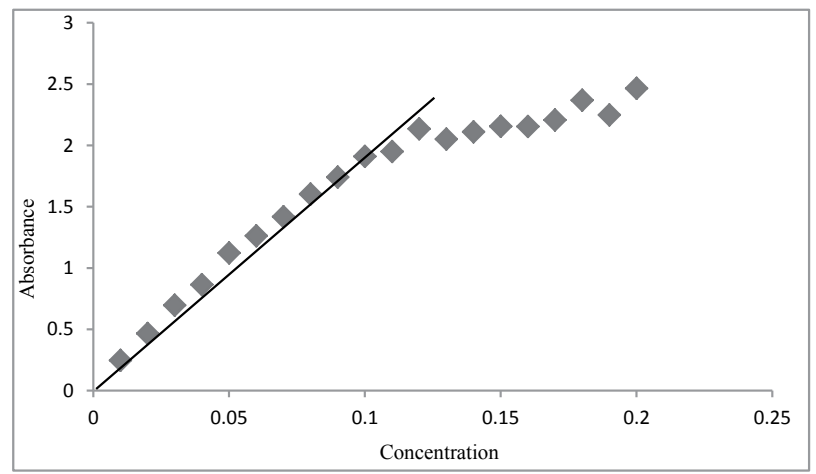

D

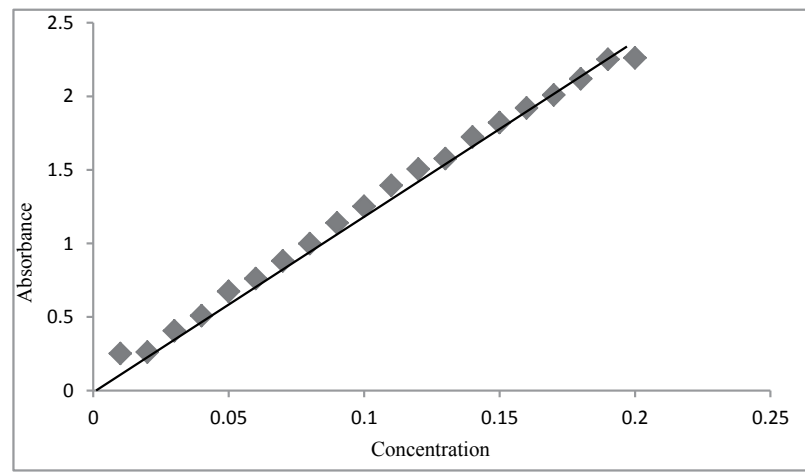

E

$\mathbf{F}$

Fig. 2: Linearity of Beer-Lambert Law for ceftiofur sodium and famotidine sodium

Linearity of Beer-Lambert Law for ceftiofur sodium at (A) $293 \mathrm{~nm}$, (B) $260 \mathrm{~nm}$, (C) $281 \mathrm{~nm}$; and famotidine sodium at (D) $293 \mathrm{~nm}$, (E) $260 \mathrm{~nm}$, (F) $281 \mathrm{~nm}$

was observed that famotidine assisted the initial release of ceftiofur sodium whereas after certain intervals, it results in overall decrease in the content of ceftiofur. This decrease in content of ceftiofur sodium was found to be more at higher temperature. These results strongly indicated that there is a possibility of formation of a new intermediate resulting from interactions between the two drugs which absorb at different absorbance value than ceftiofur sodium, which eventually led to a reduction in the content of ceftiofur in the presence of famotidine.

\section{Acknowledgements:}

Authors wish to acknowledge Lovely Professional University and Rajasthan University for providing the required facilities and infrastructure to carry out the present research.

\section{REFERENCES}

1. Hornish RE, Kotarski SF. Cephalosporins in veterinary medicine, Ceftiofur use in food animals. Curr Top Med Chem 2002;2(7):717-31.

2. Yancey RJ, Kinney ML, Roberts BJ, Goodenough KR, Hamel JC, Ford CW. Ceftiofur sodium, a broad spectrum cephalosporin: Evaluation in vitro and in vivo in Mice. Am J Vet Res 1987;48(7):1050-53.

3. Campoil DM, Clissold SP. Famotidine, pharmacodynamic and pharmacokinetic properties and a preliminary review of its therapeutic use in peptic ulcer disease and Zollinger-Ellison syndrome. Drugs 1986;32(3):197-21.

4. Foster TS, Raehi CL, Wilson HD. Disulfiram like reaction associated with a parenteral cephalosporin. Am J Hosp Pharm 1980;37(6):858-59. 
5. Taha AS, Hudson N, Hawkey CJ, Swannell AJ, Trye PN, Cottrell $\mathrm{J}$, et al. Famotidine for the prevention of gastric and duodenal ulcers caused by nonsteroidal antiinflammatory drugs. N Engl J Med 1996;334(22):1435-39.

6. Cook D, Guyatt G, Marshall J, Leasa D, Fuller H, Hall R, et al. A comparison of sucralfate and ranitidine for the prevention of upper gastrointestinal bleeding in patients requiring mechanical ventilation. N Engl J Med 1998;338(12):791-97.

7. Beck IT, Champion MC, Lemire S, Thomson AB, Anvari M, Armstrong D, et al. The second canadian consensus conference on the Management of Patients with gastroesophageal reflux Disease. Can J Gastroenterol 1997;Suppl B:7B-20B.

8. Marino EL, Vicente MT, Dominguez G. Influence of cholestyramine on the pharmacokinetic parameters of cefadroxil after simultaneous administration. Int $\mathrm{J}$ Pharm 1983;16(1):23-30.

9. Welling PG, Dean S, Selen A, Kandall MJ, Wise R. Probenecid, an unexplained effect on cephalosporin pharmacology. Braz $\mathrm{J}$ Clin Pharmacol 1979;8(5):491-95.

10. Reeves DS, Bullaock DW, Bywater MJ, Holt HA, White LO, Thornhill DP. The effect of probenecid on the pharmacokinetics and distribution of cefoxitin in healthy volunteers. Braz J Clin Pharmacol 1981;11(4):353-59.

11. Babiak LM, Rybak MJ. Hematological effects associated with $\beta$-lactam use. Drug Intell Clin Pharm 1986;20(11):833-36.

12. Gotz VP, Ryerson GG. Evaluation of tetracycline on theophylline disposition in patients with chronic obstructive airways disease. Drug Intell Clin Pharm 1986;20(9):694-97.
13. Bachmann K, Schwartz J, Forney RB, Jauregui L. Impact of cefaclor on the pharmacokinetics of theophylline. Ther Drug Monit 1986;8(2):151-54.

14. Arayne MS, Sultana N, Afzal M, Mirza AZ. Interaction studies of cephradine with H2-receptor antagonist. J Chem Soc Pak 2008;30(5):734-39.

15. Deppermann KM, Lode H, Hoffken G, Tschink G, Kalz C, Koeppe P. Influence of rantidine, pirenzepine, and aluminium magnesium hydroxide on the bioavailability of various antibiotics including amoxicillin, cephalexin, doxycycline and amoxicillin-clavulanic acid. Antimicrob Agent Chemother 1989;33(11):1901-07.

16. Sultana N, Mubeen T, Arayne MS, Ifzal R. Cefuroxime antacid interactions. Pak J Pharm Sci 2001;14(1):1-8.

17. Arayne MS, Sultana N, Bahadur SS. H2-receptor antagonist interaction with cefixime. J Chem Soc Pak 2008;595(5):72633.

18. Yukio U, Matsuhisa I, Mitsuhashi S. In vitro and in vivo antibacterial activities of CS-807, a new oral cephalosporin, Antimicrob Agent Chemother 1987;31(7):1085-92.

19. Saathoff N, Lode H, Neider K, Depperman KM, Borner K, Koeppe P. Pharmacokinetics of cefpodoxime proxetil and interactions with an antacid and an $\mathrm{H}_{2}$ - receptor antagonist. Antimicrob Agent Chemother 1992;36(4):796-800.

20. Tandon $\mathrm{N}$, Tandon $\mathrm{R} . \mathrm{H}_{2}$-receptor antagonist interactions with Ceftiofur sodium. J Chem Pharm Res 2016;8(5):831-44. 